\title{
Influence of disodium fumarate on methane production and microbial activity in Rusitec fermenters fed a mixed diet
}

\author{
M.L. Tejido, M.J. Ranilla, L.A. Giraldo and M.D. Carro ${ }^{1}$ \\ Department of Animal Production, University of León \\ 24071 León, Spain
}

\begin{abstract}
The objective of this study was to investigate the effects of disodium fumarate (FUM; 3.75 $\mathrm{mmol} / \mathrm{d}$ ) on the fermentation of a 60:40 grass hay:concentrate substrate in Rusitec fermenters. Each of eight fermenters received daily $20 \mathrm{~g}$ of substrate dry matter (DM). FUM treatment tended to increase $(\mathrm{P}=0.076)$ substrate $\mathrm{DM}$ disappearance after $6 \mathrm{~h}$ of incubation (39.8 vs $42.2 \%)$, but no effects were detected after $48 \mathrm{~h}(\mathrm{P}=0.830)$. Daily production of acetate, propionate and total volatile fatty acids (VFA) was increased by 11, 23 and 11\%, respectively, in FUM fermenters, but methane production was not affected $(\mathrm{P}=0.167)$. FUM treatment decreased $(\mathrm{P}<0.001)$ the acetate:propionate $(2.92 \mathrm{vs} 2.62)$ and methane:VFA $(0.248$ vs 0.208$)$ ratios and increased the daily flow of microbial $\mathrm{N}(\mathrm{P}=0.007 ; 140$ vs 149 $\mathrm{mg} / \mathrm{d})$. In contrast, FUM did not affect $(\mathrm{P}=0.260$ to 0.960$)$ either the numbers of total and cellulolytic bacteria or the fibrolytic activity of ruminal fluid.
\end{abstract}

KEY WORDS: disodium fumarate, methane, microbial activity, rumen, Rusitec

\section{INTRODUCTION}

Reducing ruminal methanogenesis is an important goal of ruminant nutritionists, and a range of chemical compounds (i.e. methane analogues, ionophores, unsaturated fatty acids, etc.) have been tested as potential feed additives to depress methane production. However, some of these compounds simultaneously produce adverse effects on ruminal fermentation, such as a depression of fibre degradation or reduction of microbial growth (Demeyer and Fievez, 2000). In contrast, some organic acids (malate, fumarate, etc.) have been shown to produce a decrease in methane production accompanied by an increase in both the production of volatile

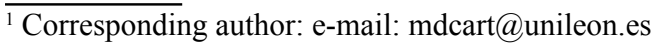


fatty acids (VFA) and diet degradation (López et al., 1999; Carro and Ranilla, 2003a,b; García-Martínez et al., 2005). Most of these studies have been conducted in short term experiments (incubations up to $24 \mathrm{~h}$ ) using batch cultures of mixed rumen microorganisms, and little is known about longer term effects of fumarate on in vitro ruminal fermentation and microbial growth. The aim of this study was, therefore, to investigate the effects of disodium fumarate on microbial growth and ruminal fermentation of a 60:40 grass hay:concentrate diet in Rusitec fermenters.

\section{MATERIAL AND METHODS}

One 18-day incubation trial was carried out using eight semi-continuous flow fermenters (Rusitec) with an effective volume of $600 \mathrm{ml}$ each. The flow through the fermenters was maintained by continuous infusion of artificial saliva ( $\mathrm{pH} 8.4)$ at a rate of $580 \mathrm{ml} / \mathrm{d}$ (dilution rate $4.03 \% / \mathrm{h}$ ). Each fermenter received daily $20 \mathrm{~g}$ dry matter $(\mathrm{DM})$ of substrate fed into nylon bags ( $100 \mu \mathrm{m}$ pore size). The substrate consisted of grass hay and concentrate (600 and $400 \mathrm{~g}$ per kg DM, respectively), and contained $939 \mathrm{~g}$ organic matter, $159 \mathrm{~g}$ crude protein, $496 \mathrm{~g}$ neutral detergent fibre (NDF) and $271 \mathrm{~g}$ acid detergent fibre (ADF) per kg DM. Concentrate was based on barley, maize, soyabean meal and mineral/vitamin premix in the proportions of 500:310:160:30 (air-dry basis). Grass hay was chopped to about $0.5 \mathrm{~cm}$ pieces and concentrate was ground through a $4 \mathrm{~mm}$ sieve. Both feed components were weighed independently and carefully mixed before applying the experimental treatments. Four fermenters received $3.75 \mathrm{mmol} / \mathrm{d}$ of disodium fumarate (Sigma-Aldrich Química, S.A., Spain) from the first day of the experiment. Fumarate was weighed and carefully mixed with the substrate immediately before this was placed into the nylon bags and fed to fermenters.

Solid and liquid fermentation inocula were collected from four rumen-cannulated sheep immediately before feeding and transferred to the fermenters within 30 min. Sheep were fed the same diet fed to fermenters and managed according to the protocols approved by the León University Institutional Animal Care and Use Committee. After 10 days of adaptation, on days 11, 12, 13 and 14, the $\mathrm{pH}$ of fermenters' fluid was determined inmediately before feeding and samples for gas and VFA determination were collected following the procedures described by Gómez et al. (2005). One nylon bag from each fermenter was collected daily, washed twice with $40 \mathrm{ml}$ of fermenter's fluid, and then washed in the cold rinse cycle of a washing machine. The DM apparent disappearance (DMD) after $48 \mathrm{~h}$ of incubation was calculated from the loss in weight after oven drying at $60^{\circ} \mathrm{C}$ for 48 $\mathrm{h}$. The growth of liquid- (LAM) and solid-phase associated microorganisms (SAM) was measured on days 15 and 16 following the procedures described by Gómez et al. (2005) and using ${ }^{15} \mathrm{~N}$ as a microbial marker. 
On days 17 and 18, the substrate administered to each fermenter was distributed into three nylon bags, one containing $18 \mathrm{~g} \mathrm{DM}$, and two containing $4 \mathrm{~g}$ DM each. The two bags containing $4 \mathrm{~g}$ were removed after $6 \mathrm{~h}$ of incubation, whereas the $18 \mathrm{~g}$ DM bag remained for $48 \mathrm{~h}$ into the fermenters. One $4 \mathrm{~g}$ bag was washed as described above to determine DMD after $6 \mathrm{~h}$ of incubation. The other $4 \mathrm{~g}$ bag was washed, its content emptied, weighed and lyophilized to determine the ${ }^{15} \mathrm{~N}$ enrichment in the non-ammonia $\mathrm{N}$ fraction, in order to estimate microbial colonization. On day 17, $4 \mathrm{ml}$ of each fermenter fluid were taken before feeding and immediately frozen at $-80^{\circ} \mathrm{C}$ for determination of enzymatic activities (endoglucanase, exoglucanase, xylanase and amylase) as described by Colombatto and Beauchemin (2003). After removing and washing the $6 \mathrm{~h}$ incubated bags, one $\mathrm{ml}$ of each fermenter's fluid was diluted through a series of tubes containing $9.0 \mathrm{ml}$ of anaerobic dilution solution. Using the $10^{-6}$ through $10^{-11}$ dilution tubes, one $\mathrm{ml}$ was placed in each of three culture tubes containing the Most Probable Number (MPN) media of Dehority et al. (1989). Total and cellulolytic bacteria concentrations were determined according to the MPN procedure of Dehority et al. (1989).

Procedures for determination of DM, ash, N, NDF, ADF, VFA, methane and ${ }^{15} \mathrm{~N}$ enrichment have been reported by Gómez et al. (2005). Data were analysed as a split-plot design with fumarate treatment as the main-plot treatment and day of sampling as the subplot treatment. In the analysis of data relative to microbial growth, microbial counts and enzymatic activities in the fermenters, day of sampling was excluded from the model. The GLM procedures of SAS (2002) were used for all statistical analyses. Significance was declared at $\mathrm{P}<0.05$, whereas $\mathrm{P}<0.10$ values were considered as trends and discussed.

\section{RESULTS AND DISCUSSION}

Fumarate supplementation did not affect either the $\mathrm{pH}$ of fermenters' fluid (6.56 and 6.61 for control and FUM, respectively; $\mathrm{P}=0.152$ ) or the amount of effluent (586 and $591 \mathrm{ml} / \mathrm{d} ; \mathrm{P}=0.788$ ). The effects of FUM on substrate disappearance and production of methane and VFA are shown in Table 1. Fumarate treatment tended $(\mathrm{P}=0.076)$ to increase DMD after $6 \mathrm{~h}$ of incubation, but the effects disappeared $(\mathrm{P}>0.05)$ after $48 \mathrm{~h}$. Supplementing the fermenters with FUM decreased methane production by $6.4 \%(0.9 \mathrm{mmol} / \mathrm{d})$, but differences with control were not significant $(\mathrm{P}=0.176)$. A reduction of methane production due to fumarate addition has been found in most of the in vitro studies, conducted with semi-continuous fermenters (López et al., 1999) or with batch cultures (Asanuma et al., 1999; López et al., 1999; Carro and Ranilla, 2003b; García-Martínez et al., 2005; Newbold et al., 2005). Differences in the magnitude of the response have, however, been variable. 
Reductions ranging from 1.4 to $7.4 \%$ have been reported by López et al. (1999) with a mixed diet, by Carro and Ranilla (2003a) with concentrate feeds, and by García-Martínez et al. (2005) with mixed diets when batch cultures were supplemented with different doses of fumarate $(4-10 \mathrm{mM})$. Greater reductions have been observed in other in vitro studies with batch cultures: Asanuma et al. (1999) reported an $11 \%$ decrease with a mixed diet and $30 \mathrm{mM}$ fumarate, and Newbold et al. (2005) found an 8\% decrease with a forage-based diet and $8 \mathrm{mM}$ fumarate. Regarding experiments conducted with fermenters, López et al. (1999) found a $17 \%$ decrease of methane production in Rusitec fermenters supplemented with $6.25 \mathrm{mmol}$ disodium fumarate.

Table 1. Influence of adding fumarate to Rusitec fermenters $(3.75 \mathrm{mmol} / \mathrm{d})$ on substrate dry matter disappearance (\%) after 6 (DMD6) and 48 (DMD48) h of incubation, incorportion of ${ }^{15} \mathrm{~N}$-ammonia in substrate residue after $6 \mathrm{~h}$ of incubation (ANI; \%), daily production $(\mathrm{mmol} / \mathrm{d})$ of methane $\left(\mathrm{CH}_{4}\right)$, acetate (Ac), propionate (Pr), butyrate (But) and total volatile fatty acids (VFA), and Ac: $\operatorname{Pr}$ and $\mathrm{CH}_{4}$ : VFA ratios (mol:mol)

\begin{tabular}{lcccccccccc}
\hline Treatment & DMD6 & DMD48 & $\mathrm{ANI}$ & $\mathrm{CH}_{4}$ & $\mathrm{Ac}$ & $\mathrm{Pr}$ & $\mathrm{But}$ & Total & $\mathrm{Ac}: \operatorname{Pr}$ & $\mathrm{CH}_{4}:$ VFA \\
\hline Control & 39.8 & 58.6 & 4.50 & 14.1 & 30.1 & 10.3 & 11.3 & 56.8 & 2.92 & 0.248 \\
Fumarate & 42.2 & 58.8 & 4.44 & 13.2 & 33.3 & 12.7 & 11.6 & 63.3 & 2.62 & 0.208 \\
s.e.d. $^{1}$ & 0.94 & 0.95 & 0.042 & 0.65 & 1.37 & 0.54 & 0.51 & 2.46 & 0.070 & 0.0100 \\
P value & 0.076 & 0.830 & 0.879 & 0.167 & 0.037 & $<0.001$ & 0.472 & 0.014 & $<0.001$ & $<0.001$ \\
\hline
\end{tabular}

${ }^{1}$ standard error of the difference

Compared to control, FUM treatment increased the production of acetate $(\mathrm{P}=0.037)$, propionate $(\mathrm{P}<0.001)$ and total VFA $(\mathrm{P}=0.014)$ by 11,23 and $11 \%$, respectively, but did not affect butyrate production $(\mathrm{P}=0.472)$. As a consequence of these changes, FUM fermenters presented lower $(\mathrm{P}<0.001)$ Ac:Pr and methane: VFA ratios, compared to control fermenters. López et al. (1999) reported that acetate and propionate production augmented by $3.5(\mathrm{P}=0.182)$ and $4.9(\mathrm{P}=0.003) \mathrm{mmol} / \mathrm{d}$, respectively, when Rusitec fermenters fed a 50:50 grass hay:concentrate substrate were supplemented daily with $6.25 \mathrm{mmol}$ of fumarate. In the present study each fermenter received daily $3.75 \mathrm{mmol}$ fumarate, and acetate and propionate production augmented by 3.2 and $2.4 \mathrm{mmol} / \mathrm{d}$, respectively $(\mathrm{P}<0.05)$. Since in both studies fermenters were supplied daily with $20 \mathrm{~g}$ of substrate, in the study of López et al. (1999) fumarate represented 5\% of substrate, whereas in the present study was $3 \%$. The decision to supplement the fermenters with a lower dose of fumarate was taken based on previous results, since García-Martínez et al. (2005) did not found differences between the effects of 4 and $8 \mathrm{mM}$ fumarate on fermentation of three different substrates in batch cultures of mixed rumen microorganisms $(3.75 \mathrm{mmol} / \mathrm{d}$ represented a final concentration of $6.25 \mathrm{mM}$ in our fermenters).

As shown in Table 2, the addition of fumarate increased $(\mathrm{P}=0.007)$ the daily flow of microorganims, and tended $(\mathrm{P}=0.083)$ to increase the flow of LAM. In 
agreement with these results, García-Martínez et al. (2005) reported that adding fumarate to batch cultures of ruminal microorganisms tended to increase $(\mathrm{P}=0.082)$ ruminal microbial growth with a high-forage diet, but found no differences when a high-concentrate diet was incubated. In our study FUM treatment did not affect total or cellulolytic bacterial numbers, whereas López et al. (1999) reported a significant increase in both bacterial populations by supplementing with fumarate. Comparison of our results to those of López et al. (1999) seems to indicate that a greater amount of fumarate than that used in our study would be necessary to modify ruminal populations, and thus, substrate fermentation in Rusitec fermenters. Supplementing with fumarate did not affect ( $\mathrm{P}=0.257$ to 0.960$)$ endoglucanase, exoglucanase, xylanase or amylase activities in ruminal fluid, which would indicate that microbial populations were not affected by fumarate.

The results seem to indicate that supplementing the fermenters with FUM stimulated the initial phases of the in vitro fermentation, but some of the observed effects of FUM on VFA production might be due to fumarate fermentation itself. Studies with greater amounts of fumarate are necessary to investigate if fumarate can modify ruminal populations.

Table 2. Influence of adding fumarate to Rusitec fermenters $(3.75 \mathrm{mmol} / \mathrm{d})$ on daily flow $(\mathrm{mg}$ microbial N/d) of liquid-associated (LAM), solid-associated microorganisms (SAM) and total microorganisms (TM), efficiency of microbial synthesis (EMS; mg microbial N/g organic matter fermented), numbers of total (TOT; x10 $/ \mathrm{ml}$ ) and cellulolytic bacteria (CEL; x $\left.10^{6} / \mathrm{ml}\right)$ and enzymatic activities in ruminal fluid

\begin{tabular}{|c|c|c|c|c|c|c|c|c|c|c|}
\hline \multirow{2}{*}{ Item } & \multicolumn{6}{|c|}{ Treatment } & \multicolumn{4}{|c|}{ Enzymatic activities ${ }^{1}$} \\
\hline & LAM & SAM & TM & EMG & TOT & CEL & END & EXO & XYL & AMYL \\
\hline Control & 72.0 & 67.7 & 140 & 28.0 & 2.38 & 2.40 & 128 & 18.6 & 471 & 397 \\
\hline Fumarate & 79.7 & 68.9 & 149 & 28.1 & 3.35 & 2.88 & 129 & 17.3 & 515 & 477 \\
\hline s.e.d. ${ }^{2}$ & 3.57 & 4.53 & 2.0 & 0.93 & 1.054 & 0.475 & 0.7 & 1.02 & 42.6 & 75.3 \\
\hline value & 0.083 & 0.811 & 0.007 & 0.845 & 0.401 & 0.363 & 0.960 & 0.257 & 0.777 & 0.26 \\
\hline
\end{tabular}

${ }^{1}$ endoglucanase (END), exoglucanase (EXO) and amylase (AMYL) activities are expressed as nmol of glucose liberated per min and $\mathrm{ml}$ of sample at $39^{\circ} \mathrm{C}$ and $\mathrm{pH} 6.5$ using carboxymethyl-cellulose, Avicel PH-101 and soluble starch as substrate, respectively. Xylanase (XYL) activity is expressed as nmol of xylose liberated from oat spelt xylan per min and $\mathrm{ml}$ of sample at $39^{\circ} \mathrm{C}$ and $\mathrm{pH} 6.5$

${ }^{2}$ standard error of the difference 


\section{REFERENCES}

Asanuma N., Iwamoto M., Hino T., 1999. Effect of the addition of fumarate on methane production by ruminal microorganisms in vitro. J. Dairy Sci. 82, 780-787

Carro M.D., Ranilla M.J., 2003a. Influence of different concentrations of disodium fumarate on methane production and fermentation of concentrate feeds by rumen microorganisms in vitro. Brit. J. Nutr. 90, 617-623

Carro M.D., Ranilla M.J., 2003b. Effect of the addition of malate on in vitro rumen fermentation of cereal grains. Brit. J. Nutr. 89, 279-288

Dehority B.A., Tirabasso P.A., Grifo Jr. A.P., 1989. Most probable-number procedures for enumerating ruminal bacteria, including the simultaneous estimation of total bacteria and cellulolytic numbers in one medium. Appl. Environ. Microbiol. 55, 2789-2792

Demeyer D.I., Fievez V., 2000. Ruminants et environnement: la méthanogenèse. Ann. Zootech. 49, 95-112

García-Martínez R., Ranilla M.J., Tejido M.L., Carro M.D., 2005. Effects of disodium fumarate on in vitro rumen microbial growth, methane production and fermentation of diets differing in their forage:concentrate ratio. Brit. J. Nutr. 94, 71-77

Gómez J.A., Tejido M.L., Carro M.D., 2005. Influence of sodium malate on microbial growth and fermentation in rumen - simulation technique fermenters receiving medium and high concentrate diets. Brit. J. Nutr. 93, 479-484

López S., Valdés C., Newbold C.J., Wallace R.J., 1999. Influence of sodium fumarate addition on rumen fermentation in vitro. Brit. J. Nutr. 81, 59-64

Newbold C.J., López S., Nelson N., Ouda J.O., Wallace R.J., Moss A.R., 2005. Propionate precursors and other metabolic intermediates as possible alternative electron acceptors to methanogenesis in ruminal fermentation. Brit. J. Nutr. 94, 27-35

SAS, 2002. SAS User's Guide: Statistics (Release 8.02). SAS Institute Inc. Cary, NC 